\title{
Static Eccentricity Fault Detection in Brushless Doubly Fed Induction Machines based on Motor Current Signature Analysis
}

\author{
$1^{\text {st }}$ Mojtaba Afshar \\ Department of Electrical and Computer Engineering \\ Isfahan University of Technology, Isfahan, Iran \\ m.afshar@alumni.iut.ac.ir \\ $3^{\text {rd }}$ Mohammad Ebrahimi \\ Department of Electrical and Computer Engineering \\ Isfahan University of Technology, Isfahan, iran \\ mebrahim@cc.iut.ac.ir
}

\author{
$2^{\text {nd }}$ Salman Abdi \\ Department of Engineering, Environment and Computing \\ Coventry University, Coventry, UK \\ ac7019@coventry.ac.uk
}

$4^{\text {th }}$ Seyed Abolfazl Mortazavizadeh

Department of Electrical and Computer Engineering

Isfahan University of Technology, Isfahan, Iran

abolafazl.mortazavizadeh@ec.iut.ac.ir

\begin{abstract}
In this paper a new rotor eccentricity fault detection method is proposed for the first time for Brushless Doubly Fed Induction Machines (BDFIMs). Due to the fact that BDFIMs are attractive alternatives to doubly fed induction machines for wind power generation, paying attention to their fault diagnosis is essential. Existing fault detection methods for conventional induction machines can not be directly applied to the BDFIM due to its special rotor structure and stator winding configurations as well as the complex magnetic fields. In this paper a new fault detection technique based on stator current harmonic analysis is proposed to detect rotor eccentricity faults in the BDFIM. The validity of the proposed fault detection method is verified by analytical winding function method and finite element analysis on a prototype D180 BDFIM.
\end{abstract}

Index Terms-Brushless doubly fed induction machines, Nested-loop rotor slot harmonics, Motor current signature analysis, Winding function method, Finite element analysis, Static eccentricity fault.

\section{INTRODUCTION}

$\mathbf{T}$ HE Brushless Doubly-Fed Induction Machine (BDFIM) is a variable medium-speed generator and drive. As a generator it is particularly attractive for wind power generation as an alternative to the well-established Doubly Fed Induction Generator (DFIG). The BDFIM is specially designed to not only retain the benefit of fractionally-rated power electronic converter in DFIG, but also eliminate the use of brushes and slip rings [1] and hence increasing the machine's reliability and reduces the overall maintenance cost. Furthermore, the BDFIM is inherently a medium-speed generator requiring only one or two-stage gearbox and hence simplifying the overall wind turbine drive train [2]. Other applications have also been reported for the BDFIM, for example, flywheel energy storage system [3] and ship generator [4].

The BDFIM's stator has two sets of three-phase windings with different pole-pairs placed in common slots. Power Wining (PW) is directly connected to the main supply and the other winding, Control Winding (CW), is fed by a bidirectional converter at variable voltage and frequency, as shown in Fig. 1. The winding pole-pair numbers are chosen to avoid direct coupling between stator windings. Coupling is enabled by a specially designed rotor called nested-loop rotor [5].

Signal-based methods have been widely used for detecting faults in the electrical machines because of their simplicity, real-time nature and less time-consuming process. Motor Current Signature Analysis (MCSA), based on analysing of the electrical current waveform, is a popular fault detecting method that has been used for detecting various types of faults including inter-turn short circuit [6] and rotor eccentricity faults [7].

Rotor Slot Harmonics (RSH) generated in stator current spectrum due to the rotor bar distribution, are well-known fault indices used in MCSA method for detecting various forms of faults such as stator inter-turn short-circuit fault [6], rotor eccentricity [8], and broken rotor bar [9]. The effects of

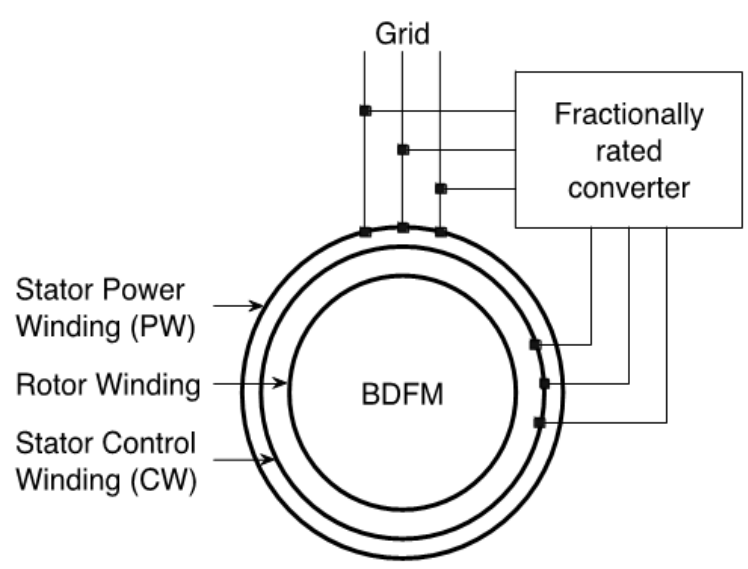

Fig. 1: A schematic of BDFIM grid connection. 
rotor eccentricity in various electrical machines' performance such as induction machines [8], and Permanent Magnet synchronous machines [10], have been studied and different fault detection methods have been proposed, but little work has been done on rotor eccentricity analysis of the BDFIMs. The effects of rotor eccentricity on the BDFIM stator back iron deflection have been studied in [11] and a special parallel winding design has been proposed to suppress the resulting deflection. In [11] an experimental work was carried out on a prototype BDFIM to measure the vibration and noise at different rotor speeds in synchronous mode of operation. A number of vibration components have been spotted in the vibration spectra caused by the machine's air-gap non-uniformity. However, no generic method has been proposed in the above work to detect the rotor eccentricity faults in the BDFIM.

In this paper, a new analytical method is proposed for the BDFIM to determine time-harmonic frequencies induced in stator winding currents by the Nested-loop Rotor Slot Harmonics (NRSHs) when the rotor is centric as well as when there is a degree of rotor eccentricity. Then, the signature frequencies in the stator currents are identified as rotor eccentricity fault indices. The proposed method is validated using analytical Winding Function method (WF) as well as Finite Element (FE) analysis of an experimental D180 BDFIM operating in synchronous mode and under rotor centric and eccentric conditions. Finally, the effects of fault severity on the magnitudes of the fault indices are investigated and it is shown that the severity of the eccentricity fault has a direct effect on the magnitude of the proposed fault indices.

\section{BRushless Doubly Fed Induction Machines}

\section{A. BDFIM Structure}

The BDFIM's stator winding consists of two sets of threephase windings with different pole-pair numbers wound in a common stator frame and supplied at different frequencies. The PW is directly connected to the grid and the $\mathrm{CW}$ is supplied with a fractional rated power converter as shown in Fig. 1. The machine can operate at three different modes, induction, cascaded and synchronous, but the main mode of operation is the synchronous mode where the PW is connected to the grid via an auto transformer and the $\mathrm{CW}$ is supplied with a power electronics convertor. The pole numbers are chosen to avoid direct coupling between PW and CW and the coupling is enabled by a special cage rotor design known as nestedloop rotor. The number of rotor nests to couple both stator magnetic fields can be determined by [12]:

$$
N_{n}=p_{p w}+p_{c w}
$$

where, $p_{p w}$ and $p_{c w}$ are $\mathrm{PW}$ and $\mathrm{CW}$ pole-pair numbers, respectively.

The BDFIM synchronous speed is determined by:

$$
\omega_{\text {synch }}=\frac{\omega_{p w}+\omega_{c w}}{p_{p w}+p_{c w}}
$$

where $\omega_{p w}$ and $\omega_{c w}$ are the supply angular frequencies of the $\mathrm{PW}$ and $\mathrm{CW}$, respectively.

\section{B. Winding Function Method}

WF method is based on the coupled magnetic circuit theory and is used to calculate stator winding inductances by means of the magntic enegy stored in the air-gap under both healthy and faulty conditions. Based on [13], the mutual inductance between the coils $A$ and $B, L_{A B}$, can be calculated as:

$$
L_{A B}=\mu_{0} r l \int_{0}^{2 \pi} n_{A}\left(\varphi, \theta_{r}\right) N_{B}\left(\varphi, \theta_{r}\right) g^{-1}\left(\varphi, \theta_{r}\right) d \varphi
$$

where $n_{A}$ is turn function for coil $A$ and $N_{B}$ is winding function for coil $B$. Also, $\mu_{0}$ is permeability of air, $l$ and $r$ are the machine's stack length and rotor diameter, respectively. The inverse of rotor air-gap function can be expressed as:

$$
g_{e}\left(\varphi, \theta_{r}\right)=g_{0}\left(1-e_{s} \cos \varphi\right)
$$

A WF model has been developed for the D180 BDFIM using which all the PW and CW inductances can be calculated under healthy and rotor eccentricity conditions. Having obtained the PW and CW inductances and by using the machines coupled circuit model followed by performing a series of transformations [12], the stator PW and CW currents can be obtained in different operating conditions.

\section{Prototype D180 BDFIM}

Table I gives detailed information for the prototype D180 BDFIM used in this study. The rotor is of a nested-loop design consisting 36 slots. As it has $p_{p w}=2$ and $p_{c w}=4$, the rotor has six nests terminated with a common end ring at one end only. Each nest is allocated 6 slots. Therefore, three concentric loops are housed within each nest. The machine is shown in Fig. 2 on the experimental rig. The Speedgoat Control system described in [14] is used to control the machine operation and $\log$ the output results used for further analysis.

\section{Finite element model development}

Linear 2D FE models have been used to model the D180 BDFIM in the synchronous mode of operation at full load conditions. The operating conditions are shown in Table II. The resulting PW and CW currents are compared with the experimental results in Fig. 3. Close agreement between the FE results and the experiment confirms the validity of the FE models. The FE linear model is particularly useful when used to verify the results obtained from analytical methods since the non-linear characteristics are ignored in both methods. The

TABLE I: Specifications for the D180 BDFIM

\begin{tabular}{cccc}
\hline \hline Parameter & Value & Parameter & Value \\
\hline Stack length & $190 \mathrm{~mm}$ & Rated power & $7.8 \mathrm{~kW}$ at 750 \\
Rated torque & $100 \mathrm{Nm}$ & Efficiency & $>92 \%$ \\
PW no of poles & 4 & PW rated voltage & $240 \mathrm{~V}$ at $50 \mathrm{~Hz}$ \\
$\mathrm{CW}$ no of poles & 8 & CW rated voltage & $172 \mathrm{~V}$ at $25 \mathrm{~Hz}$ \\
Rotor type & Nested-loop & Rotor no of slots & 36 \\
\hline \hline
\end{tabular}




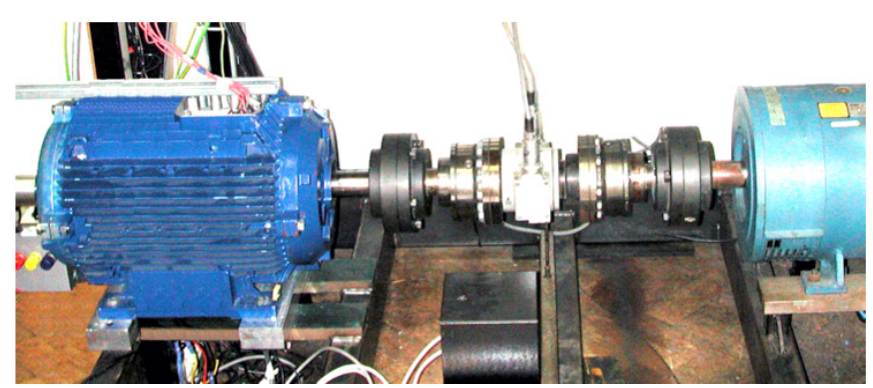

Fig. 2: D180 prototype BDFIM machine (left) on the teat rig with torque transducer and DC load machine (right)

magnetic flux pattern in synchronous mode of operation and under the operating conditions presented in Table 3 is shown in Fig. 4.

\section{MCSA Fault Detection Method}

A MCSA based method is presented to detect Static Eccentricity (SE) fault in BDFIMs. This method analyzes NRSH components as fault indices in the stator winding current spectrum to detect SE fault in a BDFIM. Due to air-gap

TABLE II: Operating conditions for the simulations and experiments in Figs. 3

\begin{tabular}{cccc}
\hline \hline Parameter & Value & Parameter & Value \\
\hline Torque & $103 \mathrm{Nm}$ & Speed & $750 \mathrm{rpm}$ \\
$V_{p w}$ & $204 \mathrm{~V}$ & PW frequency $f_{p w}$ & $50 \mathrm{~Hz}$ \\
$V_{c w}$ & $148 \mathrm{~V}$ & $\mathrm{CW}$ frequency $f_{c w}$ & $25 \mathrm{~Hz}$ \\
\hline \hline
\end{tabular}

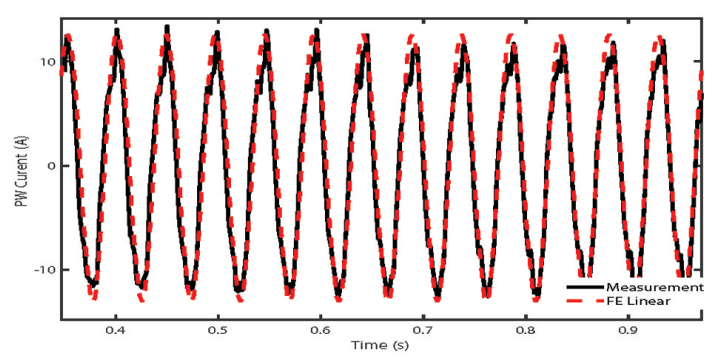

(a)

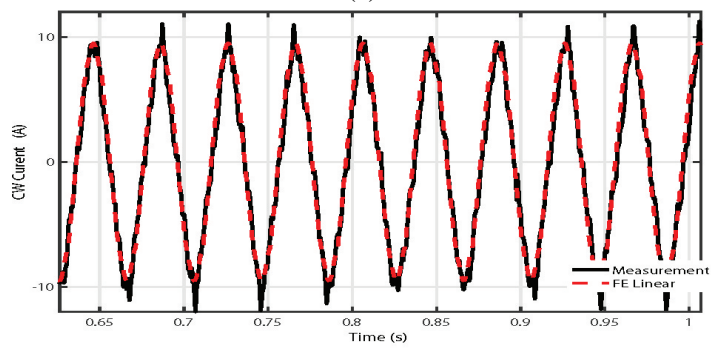

(b)

Fig. 3: D180 BDFIM stator currents in synchronous mode and at full-load condition ( $\mathrm{T}=100 \mathrm{Nm}$ ) (a) PW current (b) $\mathrm{CW}$ current

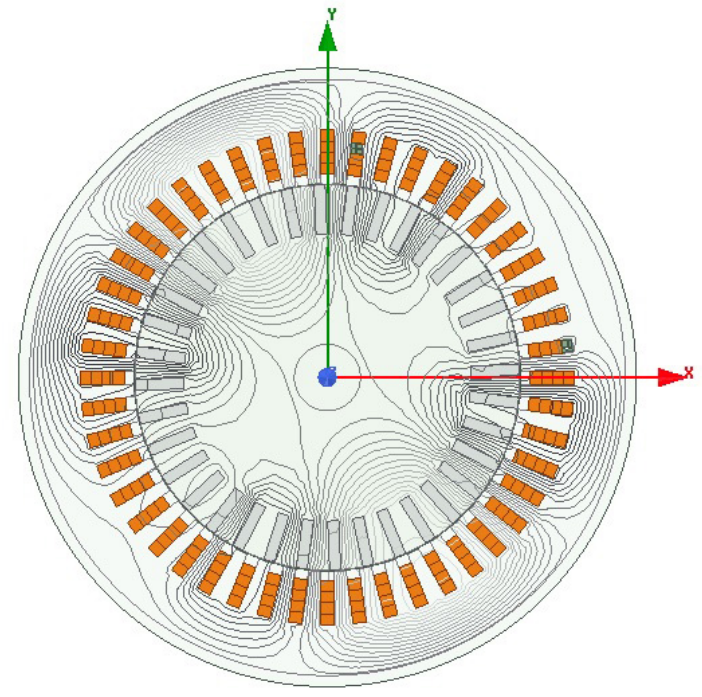

Fig. 4: Magnetic flux distribution of the BDFIM in synchronous mode of operation

non-uniformity in rotor eccentric condition, additional timeharmonics are induced within the stator winding currents spectrum by NRSHs and are known as SE fault indices. In this analysis, only PW current is considered to detect SE fault to avoid any possible noise and disturbances caused by power electronics converter swithching in the $\mathrm{CW}$ current. In the following, the BDFIM air-gap magnetic field is analytically investigated in rotor centric and eccentric condition to propose NRSH formulae for fault detection purpose.

\section{A. Healthy Condition}

Finite number of rotor slots causes space harmonics, known as rotor slot harmonics, in the air-gap magnetic field. Another source of space harmonics in the air gap magnetic field is the air-gap non-uniformity. These space harmonics together induce time harmonics in the stator winding currents. Therefore, stator current time harmonic analysis can be used as a means of detecting eccentricity faults [15]. An analytical method is proposed in this section to obtain the NRSH frequencies in the PW currents caused by the air-gap magnetic field due to the rotor eccentricity. These frequencies are used as eccentricity fault indices. The magnetic field of a distributed stator winding supplied by a sinusoidal voltage can be expressed as:

$$
\begin{aligned}
& F_{H x}\left(t, \theta_{s}\right)=\widehat{F}_{H x} \cos \left(\omega_{x} t-H_{x} \theta_{s}\right) \\
& H_{x}=(1 \pm 6 g) p_{x} \forall\left\{\begin{array}{l}
g=0,1,2, \cdots \\
x \in(p w, c w)
\end{array}\right.
\end{aligned}
$$

The fundamental component of power winding MMF in the stator reference frame can be obtained from (5) when $g$ is zero:

$$
F_{p w}\left(t, \theta_{s}\right)=\widehat{F}_{p w} \cos \left(\omega_{p w} t-p_{p w} \theta_{s}\right)
$$

Under healthy condition, the air-gap permeance function without considering saturation and slot effects can be expressed by:

$$
P \approx P_{0}
$$


By multiplying (6) and (7) the stator air-gap magnetic flux in the stator reference frame can be obtained by:

$$
\phi_{g p w}\left(t, \theta_{s}\right)=\widehat{F}_{p w} P_{0} \cos \left(\omega_{p w} t-p_{p w} \theta_{s}\right)
$$

By transfering stator magnetic flux (8) to the rotor reference frame using $\theta_{s}=\theta_{r}+\omega_{r} t$, the nested-loop rotor MMF, with the trun function given in [16], can be expressed by:

$$
F_{r p w}\left(t, \theta_{r}\right)=\widehat{F}_{r p w}\left(\omega_{r}\right) P_{0} \sin \left(\begin{array}{c}
\left(\omega_{p w}-p_{p w} \omega_{r}\right) t- \\
\left(p_{p w} \pm k N_{n}\right) \theta_{r}
\end{array}\right)
$$

According to (9), the nested-loop rotor generates MMF with $\left(p_{p w} \pm k N_{n}\right)$ harmonic orders in rotor reference frame for $k=0,1,2, \ldots$. Using (7) and (9) and $\theta_{r}=\theta_{s}-\omega_{r} t$, the rotor air-gap flux in the stator reference frame can be calculated by:

$$
\phi_{\text {grpw }}\left(t, \theta_{s}\right)=\widehat{F}_{r p w}\left(\omega_{r}\right) P_{0}^{2} \sin \left(\begin{array}{l}
\left(1 \pm \frac{k N_{n}}{p_{p w}}\left(1-S_{p w}\right)\right) \omega_{p w} t \\
-\left(p_{p w} \pm k N_{n}\right) \theta_{s}
\end{array}\right)
$$

where $S_{p w}$ is the slip respect to the power winding and can be calcualted by:

$$
S_{p w}=\frac{\omega_{p w}-p_{p w} \omega_{r}}{\omega_{p w}}
$$

Based on Faraday's Law, the magnetic flux in (10) induces voltages in the stator windings, which create time-harmonics in the PW and CW currents called Nested-loop Rotor Slot Harmonics (NRSHs). The NRSH frequencies in healthy conditon can be obtained by:

$$
\left\{\begin{aligned}
f_{S H(k)} & =\left(1+k \frac{N_{n}}{p_{p w}}\left(1-S_{p w}\right)\right) f_{p w} \\
\forall\left|p_{p w}+k N_{n}\right| \in\left|H_{p w}\right| & k=0,1,2, \cdots \\
f_{S H(k)} & =\left(1-k \frac{N_{n}}{p_{p w}}\left(1-S_{p w}\right)\right) f_{p w} \\
\forall\left|p_{p w}-k N_{n}\right| \in\left|H_{p w}\right| &
\end{aligned}\right.
$$

Where $f_{S H(k)}$ is the $k^{t h}$ NRSHs frequency component which appears in the PW current spectrum in healthy condition and $f_{p w}$ is the PW supply voltage frequency.

\section{B. Rotor eccentricity fault condition}

The radial forces acting on the surface of the rotor are very large but cancel each other when the rotor axis is aligned with the stator axis [11]. Similarly, tangential forces are balanced such that only an axially rotating moment is produced. If the rotor is eccentric, then unbalanced magnetic pull (UMP) occurs. The phenomenon can be described as an imbalance of the radial and tangential forces acting on the rotor (or stator) surface such that a net radial force is developed. This can result in the vibration and noise, and increase the possibility of the stator and rotor contact. Therefore, real-time diagnosis of rotor eccentricity is essential in order to prevent serious damages in stator and rotor windings and insulation.
Rotor eccentricity faults occur when the air-gap between the stator and rotor is non-uniform. This non-uniformity can occur in 3 different forms; static eccentricity (SE), dynamic eccentricity (DE) an a mixture of SE and DE known as mixed eccentricity [17]. In this paper only SE is studied where the rotor axis being positioned parallel to, rather than being on, the stator axis. In SE condition, the air-gap distribution is nonuniform and independent of time variation. In the presence of SE fault, the permeance function of the air-gap can be modeled as follows:

$$
P=P_{0}+P_{1} \cos \theta_{s}
$$

Substituting (13) to (6) results in stator air-gap flux under SE fault condition in the stator reference.

$$
\begin{aligned}
\phi_{g p w, S E}\left(t, \theta_{s}\right)= & \widehat{F}_{p w} P_{0} \cos \left(\omega_{p w} t-p_{p w} \theta_{s}\right)+ \\
& \frac{\widehat{F}_{p w} P_{1}}{2}\left\{\begin{array}{c}
\cos \left(\omega_{p w} t-\left(p_{p w}-1\right) \theta_{s}\right)+ \\
\cos \left(\omega_{p w} t-\left(p_{p w}+1\right) \theta_{s}\right)
\end{array}\right\}
\end{aligned}
$$

By transferring (14) to the rotor reference frame, it can be shown that the nested-loop rotor generates an MMF with harmonic orders of $p_{p w}-1 \pm k N_{n}$ and $p_{p w}+1 \pm k N_{n}$ resulted from the air-gap non-uniformity. When these harmonic orders are re-transferred to the stator reference frame using $\theta_{r}=\theta_{s}-\omega_{r} t$ and (13), the frequency of the NRSH components in the PW current spectra and under SE condition can be calculated:

$$
\left\{\begin{aligned}
& f_{S H, S E}=\left(1+k \frac{N_{n}}{p_{p w}}\left(1-S_{p w}\right)\right) f_{p w} \\
& \forall\left\{\begin{array}{l}
\left|p_{p w} \pm 1+k N_{n}\right| \in\left|H_{p w}\right| \\
\left|p_{p w} \pm 2+k N_{n}\right| \in\left|H_{p w}\right|
\end{array}, k=0,1,2, \cdots\right. \\
& f_{S H, S E}=\left(1-k \frac{N_{n}}{p_{p w}}\left(1-S_{p w}\right)\right) f_{p w} \\
& \forall\left\{\begin{array}{l}
\left|p_{p w} \pm 1-k N_{n}\right| \in\left|H_{p w}\right| \\
\left|p_{p w} \pm 2-k N_{n}\right| \in\left|H_{p w}\right|
\end{array}\right.
\end{aligned}\right.
$$

The NRSH harmonic frequencies obtained from (15) are essentially considered as the SE fault indices and hence can be used for real-time SE fault diagnosis purposes.

\section{Verification of Fault Detection Method}

In order to investigate the validity of the proposed fault detection method, a D180 BDFIM is modeled in both healthy and SE fault conditions using WF method and FE analysis in synchronous mode of operation at $580 \mathrm{rpm}$ rotor speed ( $f_{p w}=50 \mathrm{~Hz}$ and $f_{c w}=8 \mathrm{~Hz}$ ). The $\mathrm{PW}$ space harmonics are calculated based on (5) and presented in Table III. Under healthy condition and according to (12), it can be shown that the NRSH components for even values of $k$ have the same harmonic orders with the PW space harmonics given in Table 
III. Hence, the corresponding frequencies to these $k$ values are expected to be seen in the stator PW current spectrum in healthy condition. The NRSH component orders and the correspondent frequencies of the PW current are obtained using (12) for healthy condition and presented in Table IV. The NRSH component orders and frequencies of the PW current for the case of SE fault are obtained using (15) and shown in Table V.

Figs. 5a and 5b show the PW current spectrum in the synchronous mode under healthy condition obtained by WF method and FE analysis, respectively. Based on Table IV, the set of frequencies $\{50,66,166,182,282,298,398\}$ are NRSH frequencies expected to be seen in the PW current spectrum. As shown in Fig. 5, detection of those frequnecies in the PW current spectra verifies the effectiveness of the proposed method. Similarly, the PW current spectra under $20 \%$ SE fault conidtion are obtained by WF and FE simulations and depicted in Figs. 6a and 6b, repectively. Emerging of the frequncies presented in Table $\mathrm{V},\{8,108,124,224,240,340\}$, in the PW current spectra obtained by WF and FE simulations verifies the validity of the NRSH fault indices in the SE fault detection process. Therefore, these harmonic frequncies calculated by (15) can be utilized as SE fault index for diagnosis of SE faults in BDFIMs.

Furthermore, the sensitivity analysis of the NRSH fault indices to the SE fault severity levels is investigated by

TABLE III: The PW stator space harmonic orders

\begin{tabular}{cccccc}
\hline \hline $\mathbf{g}$ & $\mathbf{0}$ & $\mathbf{1}$ & $\mathbf{2}$ & $\mathbf{3}$ & $\mathbf{4}$ \\
\hline$\left|H_{p w}\right|=\left|(1+6 g) p_{p w}\right|$ & 2 & 14 & 26 & 38 & 50 \\
$\left|H_{p w}\right|=\left|(1-6 g) p_{p w}\right|$ & 2 & 10 & 22 & 34 & 46 \\
\hline \hline
\end{tabular}

TABLE IV: The NRSH component orders and frequencies in PW current in healthy condition obtained from (12)

\begin{tabular}{|c|c|c|c|c|c|}
\hline $\mathbf{k}$ & & 0 & 2 & 4 & 6 \\
\hline$\left|p_{p w}+k N_{n}\right|$ & & 2 & 14 & 26 & 38 \\
\hline $\mid\left(1+k \frac{N_{\mathrm{n}}}{p_{\mathrm{pw}}}\left(1-s_{\mathrm{pw}}\right)\right) f_{\mathrm{pw}}$ & $H z$ & 50 & 166 & 282 & 398 \\
\hline$\left|p_{p w}-k N_{n}\right|$ & & 2 & 10 & 22 & 34 \\
\hline$\left(1-k \frac{N_{\mathrm{n}}}{p_{\mathrm{pw}}}\left(1-s_{\mathrm{pw}}\right)\right) f_{\mathrm{pw}}$ & $H z$ & 50 & 66 & 182 & 298 \\
\hline
\end{tabular}

TABLE V: The NRSH component orders and frequencies in PW current in SE condition obtained from (15)

\begin{tabular}{|c|c|c|c|c|}
\hline $\mathbf{k}$ & & 1 & 3 & 5 \\
\hline$\left|p_{p w}+2+k N_{n}\right|$ & & 10 & 22 & 34 \\
\hline $\mid\left(1+k \frac{N_{\mathrm{n}}}{p_{\mathrm{pw}}}\left(1-s_{\mathrm{pw}}\right)\right) f_{\mathrm{pw}}$ & $H z$ & 108 & 224 & 340 \\
\hline$\left|p_{p w}+2-k N_{n}\right|$ & & 2 & 14 & 26 \\
\hline$\left(1-k \frac{N_{\mathrm{n}}}{p_{\mathrm{pw}}}\left(1-s_{\mathrm{pw}}\right)\right) f_{\mathrm{pw}}$ & $H z$ & 8 & 124 & 240 \\
\hline
\end{tabular}

changing the rate of SE fault level form $0 \%$ (healthy condition) up to $40 \%$, i.e. double the rate of SE fault in the previous tests. The WF and FE simulation results for this analysis are depicted in Figs. 7a, and 7b, respectively. Noticeable increase in the magnitudes of the fault indices, compared to their healthy conditions, are observed by increasing the SE fault severity levels. These uptrends confirm that the NRSH fault indices have optimal behavior for SE fault detection and are able to determine the SE fault severity level in a BDFIM.

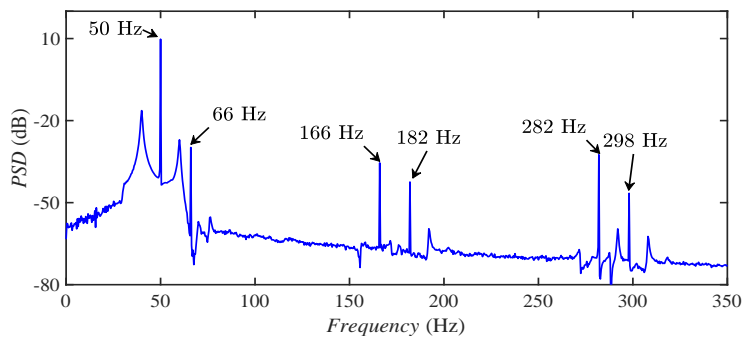

(a)

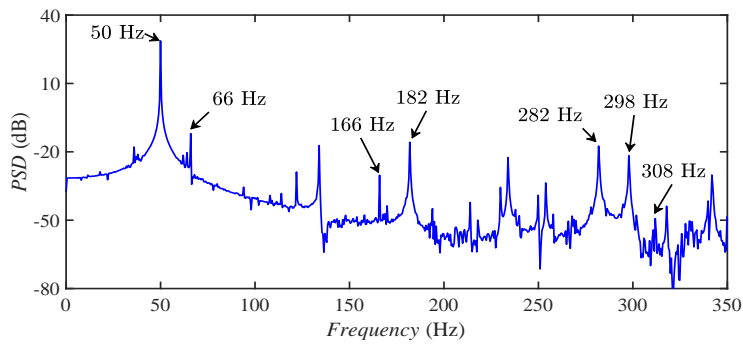

(b)

Fig. 5: The PW current spectrum in Healthy condition obtained from (a) WF method (b) FE analysis

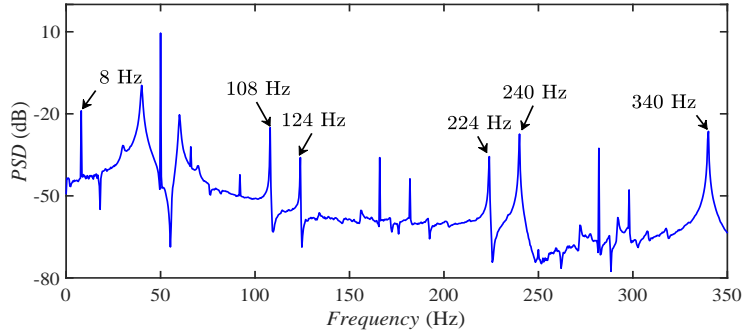

(a)

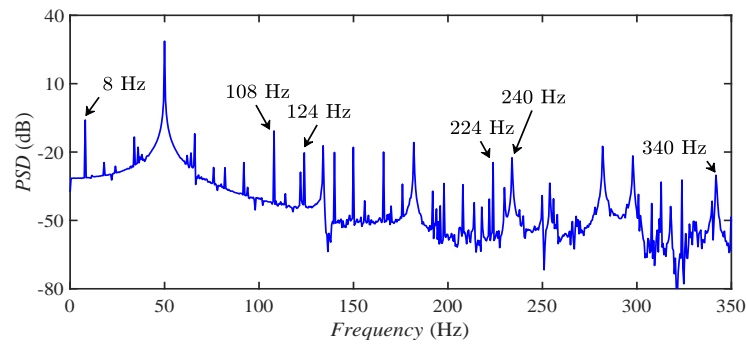

(b)

Fig. 6: The PW current spectrum under $20 \%$ SE fault obtained from (a) WF method (b) FE analysis 


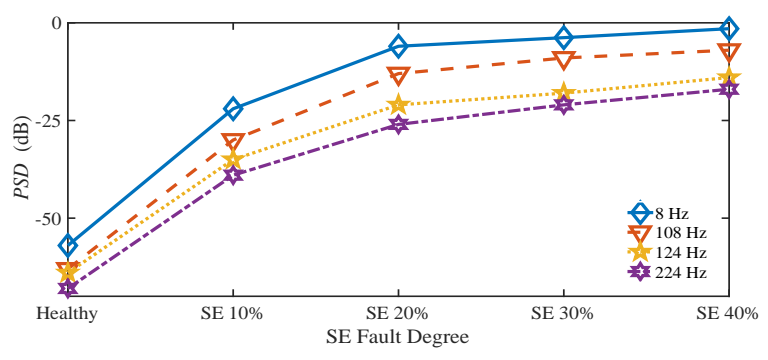

(a)

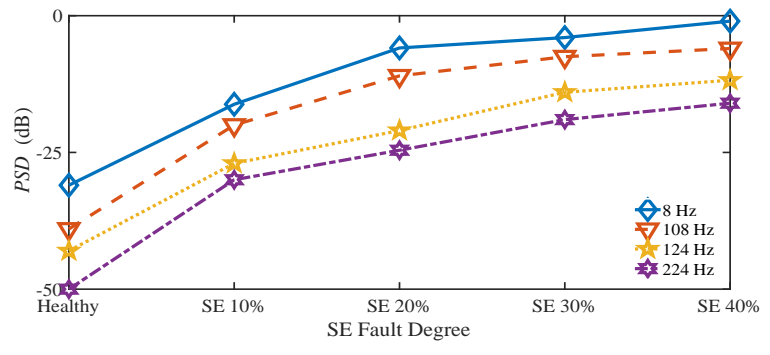

(b)

Fig. 7: Variation of the magnitudes of the SE fault indices at different SE fault levels obtained from (a) WF method (b) FE analysis

\section{CONCLUSION}

This paper has proposed a new MCSA-based fault detection method to detect rotor SE faults in the BDFIM. The air gap magnetic field has been determined analytically at both healthy and SE fault conditions. Rotor harmonic analysis has then been performed for a BDFIM with a nested-loop rotor configuration to determine the harmonic frequencies induced in the machine's stator winding currents in healthy and SE fault conditions. Based on the analysis, the signature frequencies induced in the PW current due to the presence of SE faults have been determined as fault indices. The proposed method has been verified using an analytical WF method as well as a numerical FE analysis of an experimental D180 BDFIM. The PW currents under healthy and SE fault conditions have been obtained and the same signature frequencies predicted by the fault detection technique have been observed in the current spectra confirming the validity of the proposed fault detection technique. Furthermore, fault sensitivity analysis has been performed to assess the magnitudes of the fault indices at different eccentricity levels concluding that the fault indices can also be used to determine the severity of the SE faults in the BDFIM.

\section{REFERENCES}

[1] R. A. McMahon, X. Wan, E. Abdi-Jalebi, P. J. Tavner, P. C. Roberts, and M. Jagiela, "The bdfm as a generator in wind turbines," in Power Electronics and Motion Control Conference, 2006. EPE-PEMC 2006. 12th International, pp. 1859-1865. IEEE, 2006.

[2] S. Shao, E. Abdi, and R. McMahon, "Low-cost variable speed drive based on a brushless doubly-fed motor and a fractional unidirectional converter,' IEEE Transactions on Industrial Electronics, vol. 59, no. 1, pp. 317-325, 2012.
[3] A. Ferreira, R. M. Stephan, and M. R. Araujo, "Compensating characteristics of a brushless doubly-fed machine," in 2003 IEEE International Symposium on Industrial Electronics (Cat. No. 03TH8692), vol. 1, pp. 375-378. IEEE, 2003.

[4] F. Xiong and X. Wang, "Design and performance analysis of a brushless doubly-fed machine for stand-alone ship shaft generator systems," in 2011 International Conference on Electrical and Control Engineering, pp. 2114-2117. IEEE, 2011.

[5] A. Oraee, E. Abdi, S. Abdi, R. McMahon, and P. J. Tavner, "Effects of rotor winding structure on the bdfm equivalent circuit parameters," IEEE Transactions on Energy Conversion, vol. 30, no. 4, pp. 1660-1669, 2015.

[6] R. Sharifi and M. Ebrahimi, "Detection of stator winding faults in induction motors using three-phase current monitoring," ISA transactions, vol. 50, no. 1, pp. 14-20, 2011.

[7] Y. Zhongming and W. Bin, "A review on induction motor online fault diagnosis," in Power Electronics and Motion Control Conference, 2000. Proceedings. IPEMC 2000. The Third International, vol. 3, pp. 13531358. IEEE, 2000.

[8] S. Nandi, S. Ahmed, and H. A. Toliyat, "Detection of rotor slot and other eccentricity related harmonics in a three phase induction motor with different rotor cages," IEEE Transactions on Energy Conversion, vol. 16, no. 3, pp. 253-260, 2001.

[9] W. T. Thomson and M. Fenger, "Current signature analysis to detect induction motor faults," IEEE Industry Applications Magazine, vol. 7, no. 4, pp. 26-34, 2001.

[10] B. M. Ebrahimi, J. Faiz, and M. J. Roshtkhari, "Static-, dynamic-, and mixed-eccentricity fault diagnoses in permanent-magnet synchronous motors," IEEE Transactions on Industrial Electronics, vol. 56, no. 11, pp. 4727-4739, 2009.

[11] S. Abdi, E. Abdi, and R. McMahon, "A study of unbalanced magnetic pull in brushless doubly fed machines," IEEE Transactions on Energy Conversion, vol. 30, no. 3, pp. 1218-1227, 2015.

[12] P. C. Roberts, "A study of brushless doubly-fed (induction) machines contributions in machine analysis, design and control," 2004.

[13] H. A. Toliyat, M. S. Arefeen, and A. G. Parlos, "A method for dynamic simulation of air-gap eccentricity in induction machines," IEEE Transactions on Industry Applications, vol. 32, no. 4, pp. 910-918, 1996.

[14] S. Abdi, E. Abdi, and R. McMahon, "A study of unbalanced magnetic pull in brushless doubly fed machines," IEEE Transactions on Energy Conversion, vol. 30, no. 3, pp. 1218-1227, 2015.

[15] J. Faiz, B. M. Ebrahimi, B. Akin, and H. A. Toliyat, "Comprehensive eccentricity fault diagnosis in induction motors using finite element method," IEEE Transactions on Magnetics, vol. 45, no. 3, pp. 1764 1767, 2009.

[16] H. Gorginpour, H. Oraee, and R. A. McMahon, "Performance description of brushless doubly-fed induction machine in its asynchronous and variable speed synchronous modes," Journal of Electromagnetic Analysis and Applications, vol. 3, no. 12, p. 490, 2011.

[17] V. Choqueuse, M. E. H. Benbouzid et al., "Current frequency spectral subtraction and its contribution to induction machines bearings condition monitoring," IEEE Transactions on Energy Conversion, vol. 28, no. 1, pp. 135-144, 2013. 